Troian, J., Arciszewski, T., \& Apostolidis, T. (2019). The dynamics of public opinion following terror attacks: Evidence for a decrease in equalitarian values from Internet Search Volume Indices. Cyberpsychology: Journal of Psychosocial Research on Cyberspace, 13(3), article 4. https://doi.org/10.5817/CP2019-3-4

\title{
The Dynamics of Public Opinion Following Terror Attacks: Evidence for a Decrease in Equalitarian Values From Internet Search Volume Indices
}

\author{
Jais Troian' ${ }^{1}$, Thomas Arciszewski², \& Themistoklis Apostolidis ${ }^{1}$ \\ ${ }^{1}$ Aix-Marseille University, LPS, Aix-en-Provence, France \\ ${ }^{2}$ Aix-Marseille University, Centre Psycle, Aix-en-Provence, France
}

\begin{abstract}
The tendency of terror attacks to generate increased right-wing attitudes is a direct prediction from the motivated cognition approach to political ideology (Jost, 2017). However, due to methodological and theoretical problems, evidence for this 'right-shift' hypothesis is currently mixed. To address these issues, we introduce for the first-time search volume indices (SVI) analysis to the study of public opinion dynamics by assessing the effects of exposure to the 2015 Paris terror attacks, with a focus on equalitarian values related searches in the French cyberspace. Consistent with the 'right-shift' hypothesis, we demonstrate that online collective threat salience (SVI for the word 'terror attack') predicts significant decreases in equalitarian values SVI (e.g. 'equality') 6 weeks later, but not in nonequalitarian values SVI (e.g. 'liberty'). Mixed-model analyses of SVI for the period 2012-2017 confirmed these results by showing both decrease in equalitarian values SVI and no change in non-equalitarian values SVI after 2015. These findings corroborate the 'right-shift' hypothesis at the societal level using ecological-behavioural measures of public opinion and demonstrate the value of SVI analysis for theory-testing in political psychology.
\end{abstract}

Keywords: Search Volume Indices; big data; anti-equalitarian; terror attacks; right-shift

\section{Introduction}

Research in political psychology shows that societal threats, such as terror attacks, directly increase support for right-wing parties ('right-shift' hypothesis, see Jost, 2017). Nevertheless, the current literature presents contradictory findings (Eadeh \& Chang, 2019; Jonas et al., 2014; Jost, 2017) depending how the left-right dimension is conceptualized and because of measurement issues (for instance see Kessler, Proch, Hechler, \& Nägler, 2015). Notwithstanding, a substantial part of the studies supporting the right shift was conducted prior to the current methodological reform in social psychology and may present power issues (Finkel \& Baumeister, 2019). The present contribution therefore proposes to address these methodological and theoretical issues by directly assessing the impact of threat on ideological attitudes by using ecological (online) behavioural data from millions of individuals' search engine queries.

To do this, our investigation will focus the link between terrorist threat salience and online search data in the French post-2015 terror attacks context. More specifically, we will assess threat's impact on measures of equalitarian values, which emphasize reducing disparities between demographics groups in terms of civil rights (social inequalities) and access to material resources (economic inequalities). Because equalitarianism remains a distinct feature differentiating right and left-wing ideologies (Winegard, Clark, Hasty, \& Baumeister, 2019; Winegard, Winegard, \& Geary, 2015), the present contribution should provide for a methodologically and theoretically robust test of the right-shift hypothesis in an ecological perspective. 


\section{Ideological Reactions to Threat: The 'Right-Shift' Hypothesis}

The motivational approach to political cognition (Jost, Hennes, \& Lavine, 2013) posits that political ideologies are tailored to satisfy specific psychological needs. Accordingly, research has consistently found that right-wing ideologies were associated with perceptions of threat, insecurity, heightened need for closure and structure because these worldviews best answer anxiety-uncertainty reduction needs (for a review see Jost, 2017). Here, it must be noted that no judgment is made regarding the validity and moral superiority of different political worldviews. Rather, this motivational account of political cognition sees both left and right-wing ideologies as complementary and useful to respond to different types of situations (Haidt, Graham, \& Joseph, 2009). Consequently, the theory predicts that because threatening contexts generate anxiety, individuals are expected to be more motivated to adhere to right wing ideologies and less motivated to support equalitarian policies in troubled times, which leads to a temporary decrease in public opinion's equalitarian orientation.

So far, a strong body of converging evidence supports this idea. First, on an individual level, Nail, McGregor, Drinkwater, Steele, and Thompson (2009) found that, under threat, liberal students could be led to disapprove homosexuality and support capital punishment at levels comparable to those observed among conservative students. Conversely, priming physical safety (thereby reducing feelings of threat) can make conservatives' opinions on social issues momentarily similar to those of liberals (Napier, Huang, Vonasch, \& Bargh, 2017). It also happens that evidence for such phenomena was provided by tenants of a concurrent theory of threat-regulation processes and ideology. Terror Management theorists (Rosenblatt, Greenberg, Solomon, Pyszczynski, \& Lyon, 1989) typically expect that threat will lead to polarization. In fact, the theory predicts that liberals and conservatives would commit even more to their prior worldviews following a threat. However, when investigating the psychological effects of terror attacks, these researchers found that exposure to 9/11 reminders increased both left and right-wing participants' support for a conservative president and presidential candidates in the U.S. (Landau et al., 2004).

Second, on a societal scale, Onraet, van Hiel, and Cornelis (2013) used aggregated data from an international database to demonstrate positive relationships between realistic threat indicators and right-wing attitudes $(\mathrm{N}=$ 134,516). It is also a well-established fact that threatening situations increase individuals' adherence to their national identity, prejudice expression and support for anti-immigration policies (Henderson-King, HendersonKing, \& Hathaway, 2009; Huddy, Feldman, Taber, \& Lahav, 2005). In the same vein, as Atran (2016) noted, the wave of attacks in Europe during the 2000's triggered a rise in nationalistic tendencies and more restrictive immigration policies (which are characteristic markers of right-wing ideologies), especially in France. In sum, what the literature shows so far is a general propensity of threats to generate conservative shifts in the public opinion, a phenomenon called 'right-shift' (see Jost, 2017 for a review).

\section{On Right-Wing Ideology and Equalitarianism}

Despite the seemingly robust evidence in favour of the 'right-shift' hypothesis, finer-grained investigations have raised concerns about what is meant by right wing and what attitudinal shifts actually occur under threat. For instance, it is traditionally well established that right-wing ideologies emphasize resisting social change and accepting inequality while the opposite is true of liberals (Jost, Nosek, \& Gosling, 2008). However, recent research shows that both liberals and conservatives are equally motivated to promote social change, depending on the social issue at stake (e.g. de-legalizing abortion; see Proch, Elad-Strenger, \& Kessler, 2019). Moreover, other findings point at the possibility to generate left-wing shifts under threat depending on which political party is seen as more competent to deal with the nature of the threat (health or law \& order threat may generate more support for left or right wing parties if they are perceived as 'owning' the issue, Eadeh \& Chang, 2019). Because of these issues, we limited the scope of our investigation by only operationalizing right wing ideology through attitudes towards equalitarian values only, (i.e. attitudes pertaining to one's support or aversion for demographics disparities in terms of political rights and access to resources).

Robust evidence shows that, if social change can be promoted by both left and right-wing individuals, antiequalitarianism remains a defining feature of right-wing ideology (as opposed to the left; Jost et al., 2008). This is because left-wing individuals empathize more with disadvantaged groups (Jeffries, Hornsey, Sutton, Douglas, \& Bain, 2012; Lucas \& Kteily, 2018) and have a positive bias towards low-status groups (as opposed to high status 
ones for right-wing individuals, Kteily, Rocklage, McClanahan, \& Ho, 2019). Moreover, an increase in right-wing attitudes operationalized through law \& order or safety concerns would only inform us of the public's reaction to an objective safety threat (terror attack) and not necessarily of a full ideological 'right-shift' (Eadeh \& Chang, 2019). Thus, our approach focusing on equalitarian values allows for a genuine test of the 'right-shift' hypothesis, less susceptible to theoretical bias.

Finally, most of the empirical evidence in favour of this now infamous 'right-shift' relies on self-report data in the context of large-scale surveys or laboratory experiments (see Baumeister, Vohs, \& Funder, 2007). These methods pose problems when assessing the effects of exposure to terrorist threats because of their susceptibility to contextual variability. For instance, to explain why terror attacks lead to observed right-shifts and not polarization as predicted by their theory, Terror Management researchers hypothesized that societal context (e.g. the presence of a right-wing government) might generate norm perceptions capable of influencing participants' self-reported attitudes (Burke, Kosloff, \& Landau, 2013). Thus, to test the 'right-shift' hypothesis using natural behavioural responses over prolonged periods of time (i.e. to increase its external validity and decrease the influence of social desirability), we were interested in assessing equalitarian shifts due to exposure to real-life terror attacks by using a relatively new methodological tool: SVI analysis.

\section{SVI Analysis in a Nutshell}

Automatically gathered longitudinal data of internet users (so-called 'big data') are becoming more and more accessible and the advent of cheap, powerful software has made them easier to properly analyse (Neuman, Guggenheim, Jang, \& Bae, 2014). For instance, online search engines routinely collect and give access to data regarding search queries and word entries. Such data are called Search Volumes and can be accessed through Search Volume Indexes (SVI) such as Google's trends index. This index is publicly available for almost any search query of interest. It provides researchers with the frequency at which a specific search term is typed, compared to all different search terms across languages/geographical areas (Google, 2017; for more details about Trends' algorithm specifications, see Methods, Data Collection sub-section).

The interesting fact about this kind of data is their collective and dynamic nature. Indeed, SVI provide for aggregated data from millions (or billions depending on the investigation) of individuals over time that enable researchers to tap into societal phenomena as they unfold. One of the first use of SVI in the social sciences can be found in Preis, Reith, and Stanley's (2010) analysis of word entries for tokens (i.e. terms) such as 'subprime' and 'financial crisis'. They found variations in those tokens' queries to be associated with fluctuations in stock market indexes. In other words, this was the first-time researchers demonstrated that SVI could be successfully used as a proxy for the study of complex, social phenomena. SVI also have the advantage of being longitudinal data, meaning that time series analyses can be implemented on them to assess theoretically predicted causal links.

Therefore, SVI have been used to study and predict the spread of revolution-related content from the Tunisian to the Egyptian cyberspace during the 2011 Arab Spring (Marzouki \& Oullier, 2014). Here, it was demonstrated that the correspondence between SVI and real-world societal events can be explained by the fact that SVI tap into an online pool of shared ideas, values and representations (see Marzouki \& Oullier, 2012; Marzouki \& Oullier, 2014). Consequently, SVI analysis is now a well-established research tool for forecasting and monitoring social phenomena, with applications ranging from predicting disease contagion to modelling products 'hype cycles' in consumer research (for a review see Jun, Yoo, \& Choi, 2018).

SVI reflect fluctuating, aggregated search queries from individuals: they depict a part of what goes on in the mind of a given population at a given time. This is because search queries are behavioural indicators of epistemic motivations (information seeking; Jun et al., 2018). In that sense, SVI can be understood as probing a form of macro-social phenomenon emerging from individual aggregated behaviours. More specifically, in socialpsychological terms, SVI can be seen as 'a bottom-up processing and a rather emergent property resulting from a momentum of complex interactions within the network activity' (Marzouki \& Oullier, 2014, p. 6) and seem to grasp an online form of public opinion (i.e. attitudes on a societal level). 


\section{SVI Data, a Proxy for Public Opinion?}

Consequently, it seems that SVI, though limited to single words, may constitute adequate attitudinal probes for assessing salient (prevalent) elements in a society's cyberspace. That is, SVI could be useful proxies for studying the dynamics of public opinion. Of course, as Neuman et al. (2014) rightly point out, online tweets and comments do not automatically equate to public opinion because 'Social media users are not demographically representative and diverse social media platforms undoubtedly develop local cultures of expressive style which will influence the character of what people choose to say.' (Neuman et al., 2014, p. 196). However, SVI bear upon Google queries, which broadens the demographic range (thus representativeness) of users under investigation. Moreover, these authors argue that '[...] in-person, telephonic, and online surveys of multiple-choice self-reports also fail to capture this elusive gold standard of public opinion without bias and distortion.' (Neuman et al., 2014, p. 196). Just as in their case for social media, we can reasonably assume that SVI should be regarded as a particular 'instantiation of public opinion' with its limitations, a tool that complements other biased measurements of public opinion from traditional methods in a triangulation perspective (Campbell \& Fiske, 1959). Finally, SVI reflect active interest for the topics under scrutiny, and, as would be expected from attitudinal measures, are predictive of related real-world behaviour (e.g. voting behaviour, DiGrazia, 2017).

\section{The Present Study}

The aim of the present study was to thus examine whether a form of collective threat salience could reliably predict decreases in equalitarian attitudes among the French, assuming that this dynamic process could be captured by analysing SVI changes in the French cyberspace. To do this, we decided to conduct time series analyses (Hamilton, 1994) to study the link between search queries for the token 'terror attack' (in French 'attentat', a proxy for terrorism-related threat salience) and other tokens reflecting either equalitarian values or non-equalitarian ones. We also needed another type of analyses to help corroborate the results from time series analyses. It was thus decided to conduct intervention analyses (e.g. Enders \& Sandler, 1993), on equalitarian/non-equalitarian tokens pre/post 2015 (year of the first recent wave of terror attacks that hit France). These analyses would yield robust evidence (or not) for the existence of a genuine 'right-shift' under terrorist threat using online traces of public opinion at a societal scale.

\section{Hypotheses}

According to the 'right-shift' hypothesis (i.e. threat leads to less equalitarian attitudes), time series analyses should reveal that 'terror attacks' SVI reliably and negatively predict fluctuations in SVI for tokens related to equalitarian ideologies but not for non-equalitarian ones (H1). Furthermore, compared to pre-2015 ones, post-2015 SVI of equalitarian values should decrease in prevalence while SVI related to non-equalitarian ones should display an increase, which should be qualified by an interaction effect between value type and time period $(H 2)$.

\section{Methods}

\section{Word Selection}

Threat salience. As noted earlier, we decided to use SVI of the token 'terror attacks' as a proxy for terrorismrelated collective threat salience. This token is interesting because it is not linked to a specific terror attack and is thus indicative of the extent to which terrorist-threat might be salient among our population. When selecting this token we decided not to use it in combination with other tokens (e.g. TERROR+ATTACKS+ISIS), as sometimes done in the literature (Jun et al., 2018; Marzouki \& Oullier, 2014). In fact, we needed the token to reflect general exposure to any threatening material related to terror attacks (and not necessarily those happening in France). Besides, including too specific terms might tap into content reflecting exposure to fake news or conspiracy theories (e.g. TERROR+ATTACKS+GOVERNMENT), which actually help individuals cope with threatening events (van Prooijen \& Acker, 2015).

For value tokens SVI, we selected tokens that were either related to equalitarian ideology or not ('control' tokens), but nonetheless frequently used within public discourse. 
Equalitarian SVI. Regarding the tokens related to equalitarian ideology, we decided to use 'equality' and 'fraternity' (respectively, 'égalité' and 'fraternité') because they are basic Republican values that are part of France's official motto. Also, the word 'equality' in France encompasses gender, civil, minority rights as well as wealth equality considerations (a quick Googling of the term 'égalité' brings up associations with terms as 'men', 'women', 'opportunities', 'equity', 'fraternity). We avoided terms which had an equalitarian connotation but could be linked with actual pragmatic reactions to the attacks and are commonly found in the media after such events (e.g. 'solidarity' for solidarity with the victims). Fraternity was therefore a good candidate, because it is not a commonly used term and pertains to equality between ethnic groups in France.

We also decided to use SVI entries for the token 'laïcité. In France, laïcité is a legal principle that guarantees the State and civil servants' neutral stance towards religion for ensuring freedom of religion in public places (a form of State 'secularity'; see Akan, 2009) and was first introduced by the 1905 law entitled 'On the separation between State and Cults'. It is often thought of as the 'cornerstone' of the French Republican Ideology, which refers to the 'model of integration and organization of community life [...] model which aims at ensuring freedom, equality and brotherhood' (Kamiejski, Guimond, De Oliveira, Er-Rafiy, \& Brauer, 2012, p. 53). Thus, this concept is deeply tied to the idea of religious tolerance and colorblind citizenship within French culture, hence social equality. As a concept separated from secularism, we will follow the choice of Roebroeck and Guimond (2017, in press) to keep the French word laïcité to avoid any confusion.

Non-equalitarian SVI. Finally, non-equalitarian values tokens were chosen randomly among a pool of other valuerelated words: 'justice' ('justice), 'honour' ('honneur) 'freedom' ('liberté', also part of France's motto which provides for a 'control' term regarding cultural significance). They were nevertheless tailored to represent values that were not directly related to equality per se.

It might be surprising that we did not use explicitly anti-equalitarian values in our analysis, but this was done because of the nature of SVI data itself. In fact, SVI data are made of tokens related to specific topics (here equalitarian values) that do not allow to measure attitudinal valence (i.e. individual's liking or disliking of the subject matter). To access valence, two strategies can be used. The first consists in collecting combinations of tokens by pairing the tokens with positive or negative-valence words (e.g. EQUALITY+GOOD/BAD). However, this increased specificity comes with the cost of decreased data volume, for a methodological benefit that maybe slight. In fact, it is unclear whether looking for positive or negative content on the subject matter reflects confirmation bias (thus tap into individual's 'true' attitudinal valence) or exposure to contradictory information (or even simple information seeking prior to forming an opinion). We therefore decided to use only single tokens for equalitarian values, which fluctuations reflect active interest for content related to equalitarian (whether pro or con) topics which we chose to interpret as potentially more favourable collective attitudes towards equality. This interpretation is in line with previous work, which demonstrated for instance that fluctuations in the single token 'TeaParty' predicted Tea Party mobilization across US states (DiGrazia, 2017).

Incidentally, this choice of tokens would provide for a strong test of the right-shift hypothesis, by not testing a farfetched contrast but by rather comparing equalitarian values to other, not necessarily opposed ones. For instance, 'freedom' is clearly distinct from 'equality' but is sometimes associated with it (as in France's motto or, more generally, in left-wing ideologies stating that freedom cannot be achieved without equality).

\section{Data Collection}

According to Google (2017), Trends data is 'an unbiased sample of Google search data. from both real-time random samples of the past week SVI and non-real-time data from a random sample of SVI 'pulled from as far back as 2004 and up to 36 hours before the search'. It is then 'adjusted proportionate to the time and location of a query by dividing the total searches of the geography and time range it represents to compare relative popularity [...] The resulting numbers are then scaled on a range of 0 to 100 based on a topic's proportion to all searches on all topics.' Still according to the same source, Google Trends' algorithm excludes data from 'searches made by very few people [...] duplicate searches [...] repeated searches from the same person over a short period of time'.

Time considerations. Google Trends SVI provides relative data: the weekly proportion of search index averaged by the total sum of search indexes, which changes every week. While this is not problematic for data analysis (and 
its validity), it is the reason why we must specify the time we extracted them: November the $12^{\text {th }}$ of 2017 . We extracted the last 5 years data (going back to the third week of November of 2012) for each of our tokens. The total time period was chosen according to empirical considerations. In fact, the recent wave of terror attacks in France (of amplitude never seen since the Paris bombings of 1995) started in January of 2015, with two attacks that year (November the $13^{\text {th }}$ ). As such, as can be seen in figure 1, the period before 2015 contained very few terror attacks of interest to the present investigation. We collected the data in November of 2017, and we wanted to conduct pre/post 2015 analyses, thus had 2 years of data post-2015. We estimated that 2 years of data pre-2015 would be needed to have a balanced sample. Going back from the end of 2014 (because the first terror attack of 2015 was in January), we decided to start extraction from November of 2012.

Geographical considerations. The collected data were restricted to France queries only. This was done to make sure that our analysis would mostly bear upon French citizens for issues of validity and generalizability of the findings (the present analysis focuses on the French public opinion). This gave us 261 weekly SVI by token ( $N=$ 1827 for our 7 tokens).

\section{Data Analysis}

Time series analyses and assumption checks were performed with the help of R (version 3.3, R Core Team, 2014) packages 'tseries' (version 0.10; Trapletti, Hornik \& Le Baron, 2018), 'forecast' (version 8.2; Hyndman, O'Hara-Wild, Bergmeir, Razbash, \& Wang, 2017) and 'MASS' (version 7.3; Ripley et al., 2018). Mixed model analyses (Schielzeth \& Nakagawa, 2013) were conducted using JAMOVI's GAMLj module (jamovi project, 2018).

\section{Results}

\section{Time-Series Analyses}

Before performing data analysis, we had to proceed to an experimental check of our proxy token for collective mortality salience ('terror attack) to ensure it corresponded to real world events related to terrorism. This seemed to be the case, as can be seen in figure 1. Starting from the left, the first peak between week 21 and 25 correspond to the Boston terror attack (April the $21^{\text {st }}$ of 2013, week 23). The second, dramatic increase, at week 113 is due to the 'Charlie' attacks, when armed members of ISIS killed journalists working for the satirical newspaper 'Charlie Hebdo' (January the $7^{\text {th }}$ of 2015). The third peak at week 137 and the fourth at week 157 respectively correspond to a coordinated wave of attacks in three countries (beheading of a factory worker in France, shooting at a hotel in Tunisia and a suicide bombing of a Shia mosque in Kuwait, June the $26^{\text {th }}$ of 2015) and to the November Paris attacks (November the 13 ${ }^{\text {th }}, 2015$ ). The increase observed between week 173 and 177 is due to the Brussels attacks on March the $22^{\text {nd }}$ of 2016 while the sixth peak matches the $14^{\text {th }}$ of July Nice attack at the same year, on France's National day. Then, smaller successive increases in SVI for 'terror attacks' fit the Berlin attack (week 213, December the $19^{\text {th }}$ of 2016), the London, Westminster attack (week 227, March the $22^{\text {nd }}$ of 2017), the Champs-Elysées shooting in Paris (week 231, April the $21^{\text {st }}$ of 2017), the Manchester concert attack and the London Bridge one week later (from week 237 to 239, May the $22^{\text {nd }}$ and June the $3^{\text {rd }}$ of 2017). The last observable increase (week 249) occurred at the same time as the Barcelona attacks in August the $17^{\text {th }}$.

This check indicates that SVI for the word 'terror attack' are linked with real world terrorist events. Furthermore, they seem to really reflect collective threat salience in the French cyberspace: the increases are not proportional to the number of victims in each attack (the 'material' damages of terrorism) but seem to reflect perception of highly symbolic threats within public opinion (the Charlie attacks for instance, killed 12 people but is one of the highest peaks in terms of SVI).

As for traditional data analysis, predictive tests for time series cannot be conducted before having assessed crosscorrelations between series (i.e. correlations at different time intervals between the series called 'lags'). Moreover, just like in the case of other tests, cross-correlations analyses cannot be performed if some preliminary assumptions are not thoroughly assessed and met. These assumptions pertain to normality and homoscedasticity. Normality can be tested through traditional normality tests, while homoscedasticity must be checked through tests called stationarity tests. This is done to clean time series from noise that can potentially 
hide interesting patterns but also to prevent ourselves from finding and interpreting spurious correlations (Granger \& Newbold, 1974).

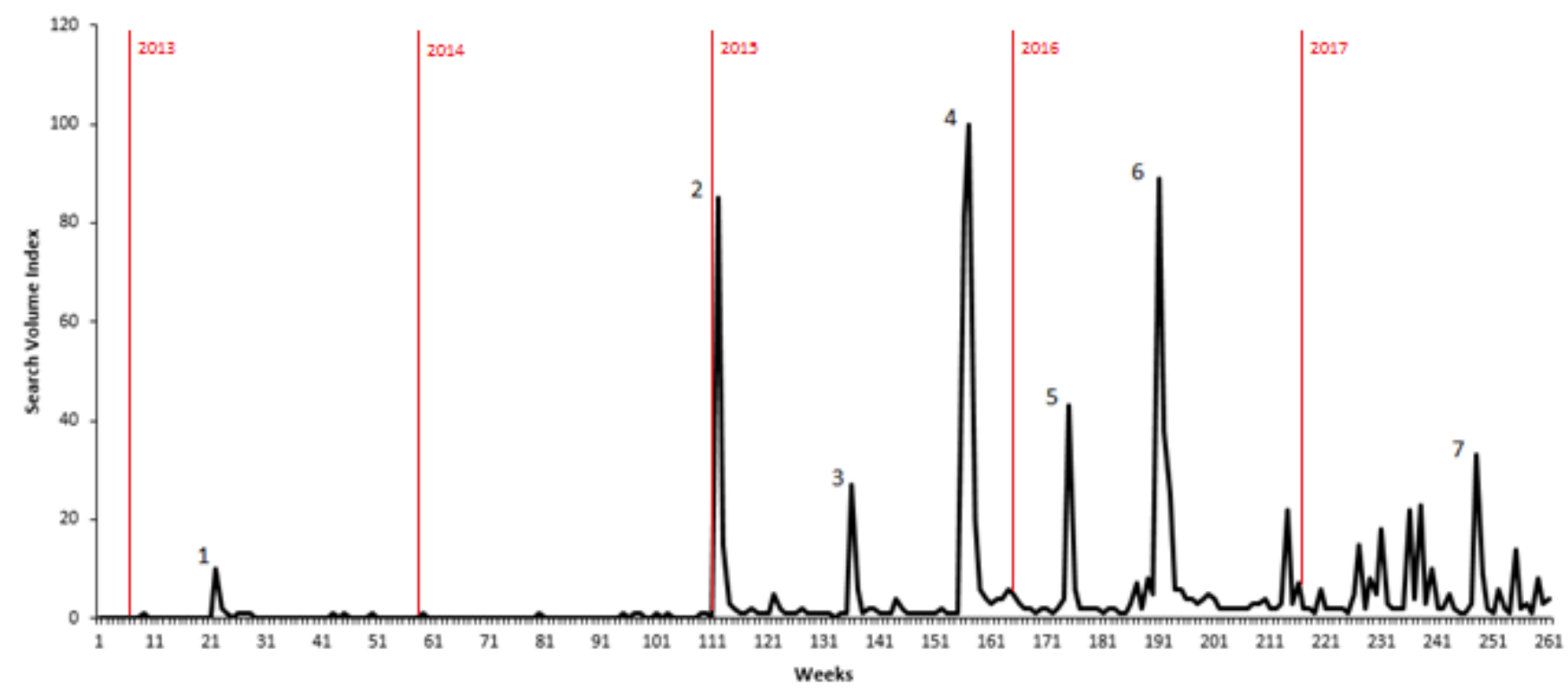

Figure 1. Chronogram of weekly levels of SVI for the token 'terror attack' from November the $18^{\text {th }}$ of 2012 (week 1) to November the $12^{\text {th }}$ of 2017 (week 261). Numbers indicate occurrences of real-world terror attacks, from left to right in:

(1) Boston, (2) Charlie Hebdo facilities, (3) Tunisia (4) Paris (5) Brussels (6) Nice (7) Barcelona. Red bars represent years, from 2013 (left) to 2017 (right).

Normality tests. Shapiro-Wilk tests (Shapiro \& Wilk, 1965) were conducted on our 7 SVI variables. All were found to deviate from normality: 'liberty' $(W=0.81, p<.001)$, 'equality' $(W=0.98, p<.001)$, 'fraternity' $(W=0.76, p<.001)$, 'laïcité' $(W=0.73, p<.001)$, 'terror attacks' $(W=0.32, p<.001)$, 'honour' $(W=0.55, p<.001)$, 'justice' $(W=0.94, p<$ .001). To palliate this non-normality, we computed lambda parameters for each factor and power transformed them accordingly (Box \& Cox, 1964; see Osborne, 2010 for further details).

Stationarity tests. Kwiatkowski-Phillips-Schmidt-Shin (KPSS, Kwiatkowski, Phillips, Schmidt, \& Shin, 1992) tests were implemented to assess the extent to which variances of our time series changed over time (that is, if they are non-stationary). This test assesses a null hypothesis of stationarity: if it is significant, then our time series are not stationary and need further transformation (first-order differentiation see Al-Osh, 1987; Marzouki \& Oullier, 2014) before they can be analysed. Results for the tests before and after transformation (if non-stationary, maximum lags for error correction $I=3$ ) of our time series can be found in Table 1 .

Table 1. Results of the KPSS unit root tests for our time series before and after transformation.

\begin{tabular}{|c|c|c|c|c|c|c|}
\hline \multirow{2}{*}{ TimeSeries } & \multicolumn{3}{|c|}{ Before transformation } & \multicolumn{3}{|c|}{ After Transformation } \\
\hline & Level & $p$-value & Stationary & Level & $p$-value & Stationary \\
\hline Liberty & 0.21 & $>.10$ & Yes & - & - & - \\
\hline Laïcité & 1.06 & $<.01$ & No & 0.02 & $>.10$ & Yes \\
\hline Equality & 2.91 & $<.01$ & No & 0.03 & $>.10$ & Yes \\
\hline Fraternity & 1.30 & $<.01$ & No & 0.02 & $>.10$ & Yes \\
\hline Terror Attack & 4.13 & $<.01$ & No & 0.01 & $>.10$ & Yes \\
\hline Honour & 2.18 & $<.01$ & No & 0.01 & $>.10$ & Yes \\
\hline Justice & 0.74 & $<.01$ & No & 0.06 & $>.10$ & Yes \\
\hline
\end{tabular}



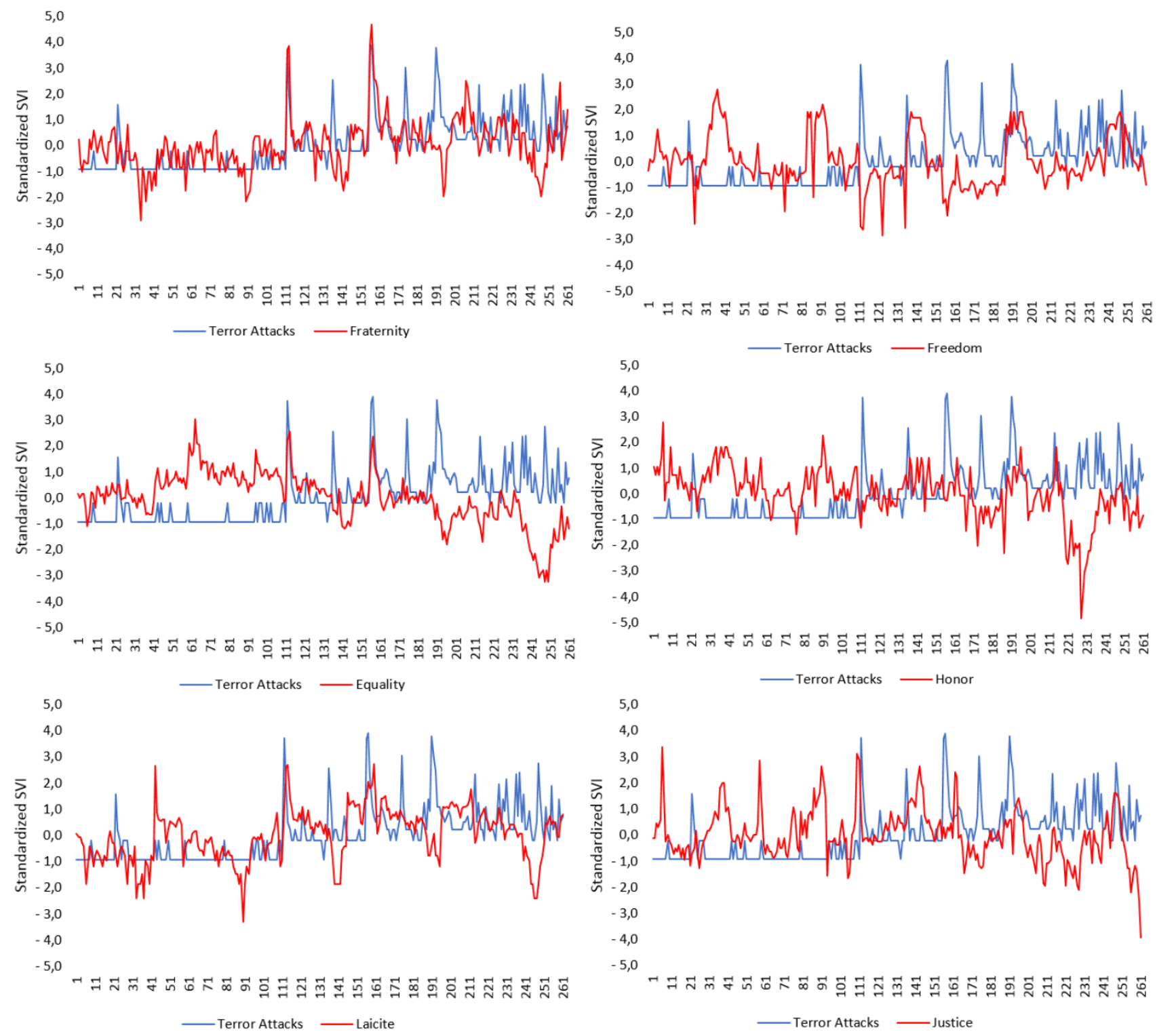

Figure 2. Chronograms of equalitarian value SVI (left side) and non-equalitarian value SVI (right side) including 'terror attack' SVI for comparison. The $\mathrm{x}$-axis represent time (in weeks) and the $\mathrm{y}$-axis represent standardized SVI for tokens.

Cross-correlations. Since our series satisfied (at least partially) normality assumptions and achieved stationarity, we decided to compute cross-correlations between SVI for 'terror attack' and our seven other time series. Crosscorrelations are indicative of correlation levels between an $x$ variable (here collective threat salience) and a $y$ variable (our equalitarian/non- equalitarian values) at some specified lags (time difference between series). If significant cross-correlations are found at negative lags, $x$ is said to lead $y$, meaning that $x$ predicts future changes in $y$ (it is the reverse for positive lags, for more details about these types of analyses see Box, Jenkins, \& Reinsel, 1994). That is why we will be interested in correlation values at negative lags between collective threat salience and equalitarian/non-equalitarian values time series. Given theoretical relevance (there is no a priori reason to expect durable effects over too prolonged periods of time) and for the sake of clarity, we decided to analyse lags until 6 months ( 24 weeks) but reduced them to 21 , lag of the last significant result we obtained in that period.

Computed-cross correlations (see figure 2; Appendix 1 for the complete table of results) revealed no significant correlations at negative lags between 'terror attack' SVI and non-equalitarian values. Interestingly, we observed significant positive correlations at lag 0 between 'terror attack' SVI and both 'equality' $(r=.26, p<.05)$ and 'fraternity' $(r=.19, p<.05)$. As expected, variations in 'terror attack' SVI positively predicted decreases in 'equality' (lag $=-6, r=$ $-.12, p=.05)$, 'fraternity' (lag $=-6, r=-.14, p<.05)$ and 'laïcité' (lag $=-6, r=-.14, p<.05)$. We also observed that threat salience predicted increases in 'laïcité' 21 weeks later (lag $=-21, r=.16, p<.05$ ), which was not expected but is very significant for the analysis of the French public opinion post-terror attacks and will be further discussed later. Cross-correlations patterns were then ordered through hierarchical clustering (Euclidian distance, complete 
linkage method, Babicki et al., 2016). Results can be seen in figure 3 and confirmed the similarly equalitarian nature of 'equality' and 'fraternity' (common cluster) but not of 'laïcité', which stands aside among the cluster of nonequalitarian values.

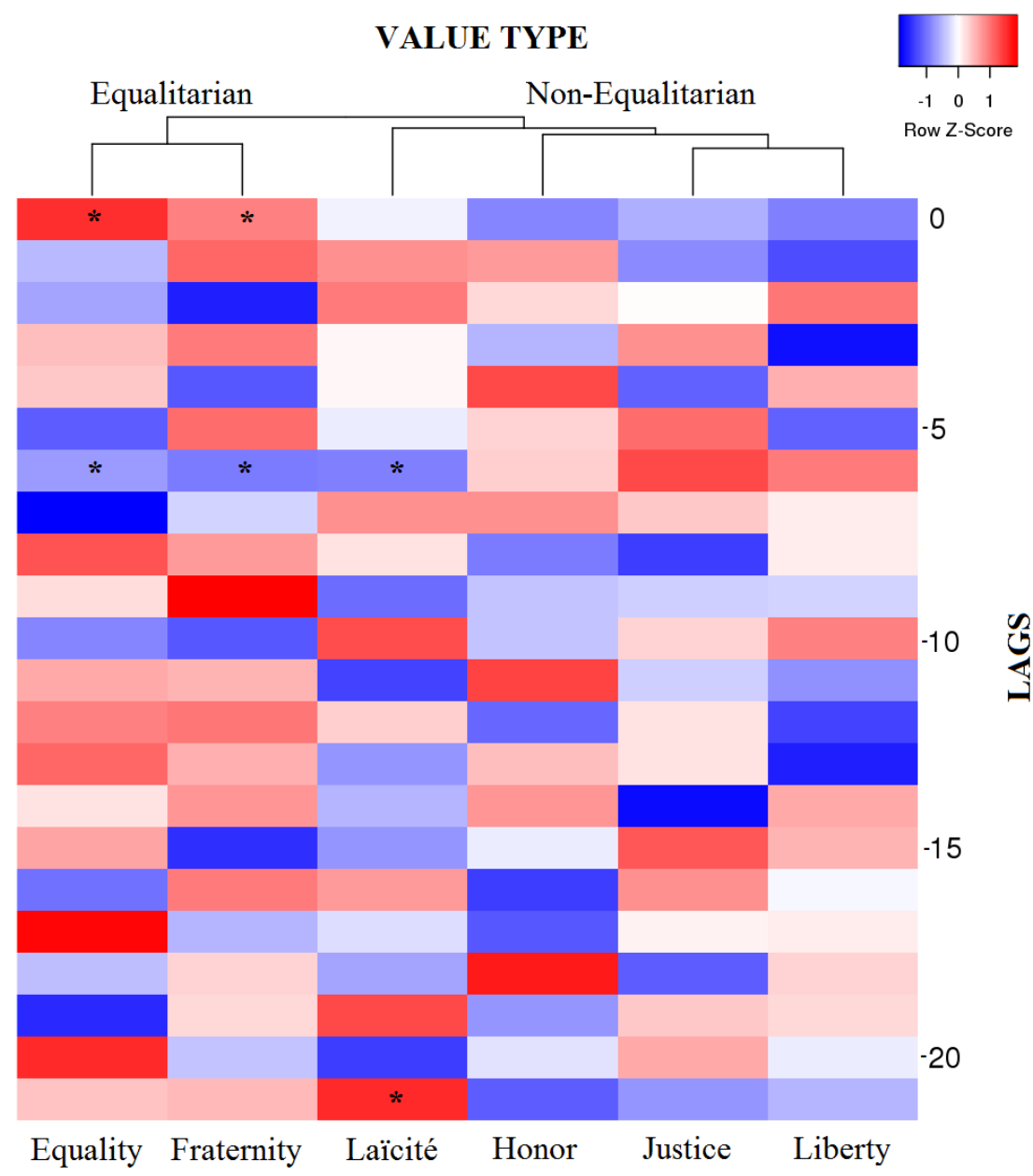

VALUES SVI

Figure 3. Hierarchical clustered heatmap of Pearson's product moment correlation $r$-values as a function of lags between 'terror attacks' SVI and values SVI. 1 Lag $=1$ week. ${ }^{*} p \leq .05$.

Lagged Regressions. Now that cross correlations were found between some of our time series, confirmatory analyses were needed to ensure that (a) a linear effect of time can be excluded as a confound (b) these one-toone relationships hold in multivariate analyses (c) parameters are adequately estimated through a single model. Regular OLS regression models revealed no significant effect of time (weeks) on any of our time series (all $p$ 's > .60). This allowed us to exclude time as a potential confound and to compute a lagged linear multivariate model using 'terror attack' SVI as our independent variable and lagged SVI of 'equality' $(I=-6)$, 'fraternity' $(I=-6)$, 'laïcité' $(I=$ -6) as dependent variables. The lagged variables were created by re-matching every point of our values to collective threat salience with a minus 6 delay. Thus, we computed a linear multivariate model of fluctuations in 'terror attack' SVI on future ( 6 weeks ahead) values of 'equality', 'fraternity' and 'laïcité' SVI, achieving true temporal prediction. The overall model was significant, Wilks $\lambda=.97, F(3,250)=2.96, p=.035, r^{2}=.03$. It confirmed that threat salience predicted small but systematic decreases in 'fraternity', $F(1,252)=5.66, p=.018, r^{2}=.02$, 'laïcité', $F(1,252)=5.44, p$ $=.02, r^{2}=.02$ and in 'equality' $F(1,245)=3.78, p=.053, r^{2}=.02$ within 6 weeks. Hence, $H 1$ cannot be rejected.

Intervention analysis. After finding support for our hypothesis using a collective subjective indicator of threat, we wanted to corroborate our findings using an objective indicator, that is, anti-equalitarian shifts after the 2015 terror attacks. To conduct such intervention analyses (Box \& Tiao, 1975), we had to start back from the raw data and check again their fit with pre-analyses assumptions. Data were aggregated (value tokens were considered as subjects) a value type variable was computed (Equalitarian $=1$, Non-Equalitarian $=0$ ) along with a period factor (Pre-attack = 0; Post-attack =1). Because of its specific profile, which reflects a different meaning than other clearly 
equalitarian SVI (see the discussion part), 'laïcité' was excluded from the analysis, leaving us with $N=1305$ data points. They were not normally distributed $(W=0.97, p<.001)$, and according to Box-Cox power transformation rules, were log-transformed. However, the data were stationary (thus achieved homoscedasticity, KPSS $=.16, p=$ .10).

A mixed-model (Schielzeth \& Nakagawa, 2013) containing one nested random effect (period, week and year) was computed according to the following equation: $\log ($ trend $) \sim 1+(1 \mid$ year/period/week $)+$ valuetype + valuetype:period. It was deemed adequate (AIC $=1672.5$, Log-Likelihood $=-829.2$ ), yielded a significant main effect of value type $t(487.97)=5.91, p<.001, d=.54$ and the predicted interaction effect between value type and period emerged, $t(179.31)=-2.89, p=.004, d=.43$. As can be seen on figure 4 , the interaction is driven by a decrease in Equalitarian value related SVI post-2015. Therefore, $H 2$ cannot be rejected.

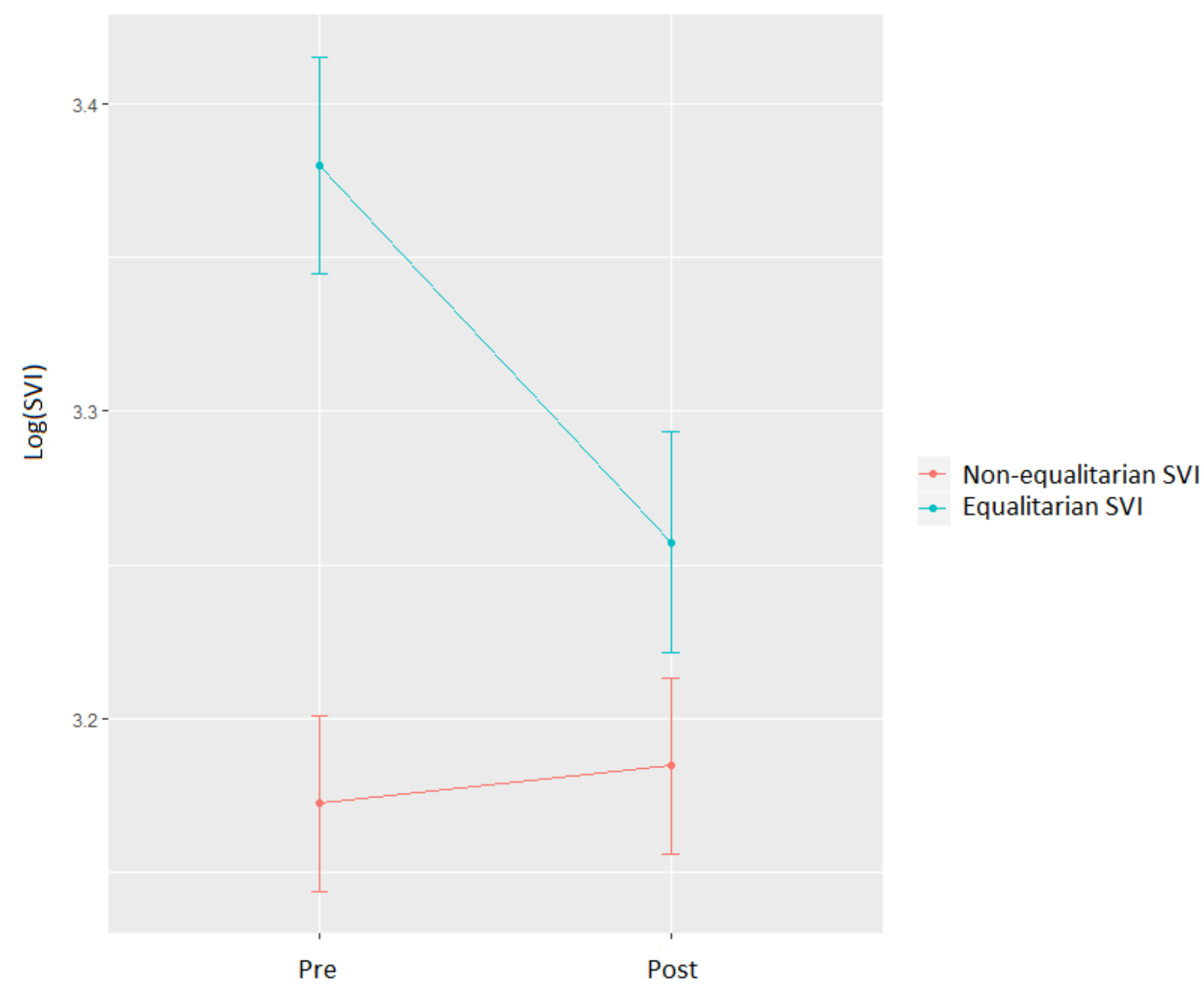

Figure 4. Mean SVI (log-transformed) for Non-Equalitarian and Egalitarian values pre-post the 2015 Paris attacks. Error bars represent SE.

\section{Discussion}

Our results corroborate the right-shift hypothesis with regards to equalitarian values. Also, this is one of the firsttime evidence is provided for a societal right-shift using naturalistic behavioural indicators. Moreover, these results are more robust to social context since our data covered a time period in France that included two different political contexts (first under a social-democrat government and from June of 2017 a right-wing government).

First, cross-correlation analyses revealed that increases in 'terror attack' SVI predict decreases in prevalence of three seemingly equalitarian values (equality, fraternity and 'laïcité') within the French cyberspace. This predictive 
character of collective threat salience was confirmed through multivariate analyses which revealed a systematic, small ( $r=.14$ thus $d=.28$ ) delayed effect. Also, threat salience was positively synchronized (at lag 0 ) with both equalitarian and fraternity values, which is very interesting because it may be indicative of the typical media, public and political class' immediate reactions to terror attacks in France, which consists in promoting equalitarian values, national unity and trying to prevent stigmatization of minorities (Maghrebi ones in the case of Islamist terrorism).

Interestingly, analyses revealed a significant impact of the 2015 terror attacks in terms of value prevalence. Moreover, they showed an unexpected increase in laïcité at lag 21, which is very interesting from a social-political point of view. In fact, shifting from its original meaning (i.e. laïcité states that civil servants and the State must remain politically and religiously neutral to allow freedom of expression and religion in the public sphere), more and more French people have started to believe that laïcité must be applied to individuals and that it relegates the expression of one's religious affiliation (such as wearing visible religious signs) to private settings (Vauchez \& Valentin, 2014). The rise of those beliefs is closely linked with increasing debates surrounding the wearing of hijab by Muslim women in French public places (Nugier, Roebroeck et al., 2016). This, along with the idea that Islam and its practices are fundamentally incompatible with laïcité because they are too remote from France's alleged 'Christian cultural roots' and go against gender equality principles (this prevalent use of gender equality principles to express nationalistic sentiments has been labelled 'femonationalism' see Hancock \& Mobillion, 2019).

Consequently, social psychologists have found these beliefs about laïcité to be correlated with expressed prejudice towards people of North African descent (Guimond, de la Sablonnière, \& Nugier, 2014; Kamiejski et al., 2012) and Generalized Prejudice (Roebroeck \& Guimond, 2015). Nugier, Oppin and colleagues (2016) also successfully demonstrated that beliefs about laïcité may have a prejudice-justification function (Crandall \& Eshleman, 2003). Also, Roebroeck and Guimond (in press) showed that adherence to laïcité in general plays a key functional role as a collective means for managing intergroup threat: it acts as a malleable ideology mobilized after both symbolic and realist threats (i.e. an exclusive 'inclusive' principle; Tetreault, 2013). Indeed, since 2015, debates surrounding the definition of laïcité have raged through the public opinion and constituted a major campaign theme during the 2017 presidential election.

The only limitation to our interpretation here is that prevalence of laïcité SVI cannot inform us about the prevalence of specific beliefs about it. However, the cross-correlation pattern between threat salience and laïcité SVI may be indicative of a polarization of public opinion surrounding this issue, first rejecting a equalitarian laïcité within 6 weeks to engage in promotion of a distorted (hence public debates), anti- equalitarian version of it 15 weeks later. This analysis is in line with results from traditional polls indicating that (1) a majority of French citizens thought the laïcité issue was too prevalent in the 2017 presidential election (2) Marine Le Pen (extreme-right) voters thought that laïcité was under threat and meant preserving traditional French identity in contrast with Emmanuel Macron (center-right) voters for whom laïcité meant freedom of religion (IPSOS, March, 2017).

Finally, our mixed model analysis was able to confirm that terror attacks had a positive effect on prevalence of non-equalitarian values. Again, this result is in line with results from traditional survey studies of the impact of the 2015 Paris attacks upon French individuals (authoritarian shift, see Vasilopoulos, Marcus, \& Foucault, 2018). Incidentally, we were able to test two concurrent hypotheses on a macro-social scale. In fact, as stated earlier, a Terror Management approach would predict that terrorist attacks will lead individuals to reduce death-related anxiety through ideological polarization (e.g. Pyszczynski, Solomon, \& Greenberg, 2003; Weise, Arciszewski, Verlhiac, Pyszczynski, \& Greenberg, 2012). However, from a motivated political cognition perspective (Jost et al., 2008) we have seen that threat indeed lead to a global, temporary anti-equalitarian shift in public opinion's orientation.

Despite these interesting results, some methodological constraints should be considered. First SVI are reduced ways to access abstract and nuanced cultural values (as in the case of laïcité), which limits their intrinsic explanatory power. Moreover, SVI constitute a proxy to a form of online public opinion which is by no means a 'fleeting' pool of ideas. If they tap into an emergent property of aggregated micro-individual behaviour, it begs the question: what kind of behaviour? Do SVI stem from confirmatory online searches (i.e. people wanting to comfort their opinions) which would increase with anxiety or do they reflect a true epistemic motivation (i.e. uncertainty reduction as regards the object of inquiry)? Unfortunately, further experimental investigation of individual online search behaviour would be needed to refine our understanding of SVI-based measures. 
Moreover, if the predictive power of collective threat salience seems robust, its effect and that of the mixed model was small (e.g. non-significant slopes) which is indicative of the difficulty to properly separate signal from noise in big data analysis, because of the data's nature (which includes information about both structural, economic factors and lower level ones such as individual differences leading to complex multilevel interaction patterns). This can be seen by looking at the results of mixed model analyses even if the obtained interaction effect was in line with typical effect sizes in social psychological research ( $d=.43 \mathrm{vs;} d=.42$, see Richard, Bond, \& Stokes-Zoota, 2003). Also, we cannot exclude the possibility that other value tokens might have induced different results. Hence, further replications of these kinds of analyses are needed, both in a within and a cross-cultural way.

A final puzzle regards the temporal delays between our SVI series. The present results converge, for instance, with observations from survey data showing that attachment to Laïcité decreases beginning at the third week following the Charlie attacks (Cohu, Maisonneuve, \& Testé, 2016). Though SVI data does not reflect attitudinal valence towards the token (here Laïcité), we can reasonably assume that a decreased prevalence of token searches in the cyberspace partially reflects decreased salience and societal focus on the issue reflected by the token. This is because SVI queries reflect active interest in the researched topic. We may thus interpret decreased Laïcité token prevalence as decreased collective interest in the topic, which does not amount but should partly reflect decreased self-reported attachment to Laïcité. However, we still do not have a clear idea or theoretical reason why ideological reactions to collective threat should take 6 weeks to deploy. Investigating this issue, for instance through psychological theories pertaining to emotional regulation dynamics (Gilbert, Lieberman, Morewedge, \& Wilson, 2006) might lead to considerable theoretical advances. That is why we argue that analyses of this kind can highlight interesting trends in public opinion and do allow for theory testing on a macrosocial scale.

\section{Conclusion}

Within the boundaries of the above-mentioned limitations, we are confident that these SVI analyses allowed us to highlight a right-shift in the French cyberspace following the 2015 terror attacks in an ecological way and to study its dynamical features. Because our results converge with some obtained through traditional survey methods, we think SVI might provide powerful predictors of real-life political outcomes and further research should be carried out in a triangulation perspective (Campbell \& Fiske, 1959; Cohen, Nisbett, Bowdle, \& Schwarz, 1996). SVI data may constitute a promising tool for enriching theoretical models in the field of political psychology and bypassing methodological issues inherent to more traditional data collection methods.

\section{Acknowledgement}

The authors wished to thank the editor and the three anonymous reviewers for their invaluable contribution and thorough scrutiny on the present manuscript. The authors would also like to thank Dr. Bikas Chandra Bhattarai for his advice regarding time series analyses.

\section{References}

Akan, M. (2009). Laïcité and multiculturalism: The Stasi Report in context. The British Journal of Sociology, 60, 237256. https://doi.org/10.1111/j.1468-4446.2009.01229.x

Al-Osh, M. A., \& Alzaid, A. A. (1987). First order integer-valued autoregressive (INAR (1)) process. Journal of Time Series Analysis, 8, 261-275. https://doi.org/10.1111/j.1467-9892.1987.tb00438.x

Atran, S. (2016). The devoted actor: Unconditional commitment and intractable conflict across cultures. Current Anthropology, 57(Suppl. 13), S192-S203. https://doi.org/10.1086/685495

Babicki S., Arndt, D., Marcu, A., Liang, Y., Grant, J. R., Maciejewski, A., \& Wishart, D. S. (2016). Heatmapper: Webenabled heat mapping for all. Nucleic Acids Research, 44(W1), W147-W153. https://doi.org/10.1093/nar/gkw419 
Baumeister, R. F., Vohs, K. D., \& Funder, D. C. (2007). Psychology as the science of self-reports and finger movements: Whatever happened to actual behavior? Perspectives on Psychological Science, 2, 396-403.

https://doi.org/10.1111/j.1745-6916.2007.00051.x

Box, G. E. P., \& Cox, D. R. (1964). An analysis of transformations. Journal of the Royal Statistical Society. Series $B$ (Methodological), 26, 211-252. Retrieved from http://www.jstor.org/stable/2984418

Box, G. E. P., Jenkins, G. M., \& Reinsel, G. C. (1994). Time series analysis: Forecasting and control (3rd ed.). Upper Saddle River, NJ: Prentice Hall.

Box, G. E. P., \& Tiao, G. C. (1975). Intervention analysis with applications to economic and environmental problems. Journal of the American Statistical Association, 70(349), 70-79.

https://doi.org/10.1080/01621459.1975.10480264

Burke, B. L., Kosloff, S., \& Landau, M. J. (2013). Death goes to the polls: A meta-analysis of mortality salience effects on political attitudes. Political Psychology, 34, 183-200. https://doi.org/10.1111/pops.12005

Campbell, D. T., \& Fiske, D. W. (1959). Convergent and discriminant validation by the multitrait-multimethod matrix. Psychological Bulletin, 56, 81-105. https://doi.org/10.1037/h0046016

Cohen, D., Nisbett, R. E., Bowdle, B. F., \& Schwarz, N. (1996). Insult, aggression, and the southern culture of honor: An "experimental ethnography". Journal of Personality and Social Psychology, 70, 945-960.

https://doi.org/10.1037/0022-3514.70.5.945

Cohu, M., Maisonneuve, C., \& Testé, B. (2016). The "Charlie-Hebdo" effect: Repercussions of the January 2015 terrorist attacks in France on prejudice toward immigrants and North-Africans, social dominance orientation, and attachment to the principle of laïcité. International Review of Social Psychology, 29, 50-58.

http://doi.org/10.5334/irsp.59

Crandall, C. S., \& Eshleman, A. (2003). A justification-suppression model of the expression and experience of prejudice. Psychological Bulletin, 129, 414-446. https://doi.org/10.1037/0033-2909.129.3.414

DiGrazia, J. (2017). Using Internet search data to produce state-level measures: The case of tea party mobilization. Sociological Methods \& Research, 46, 898-925. https://doi.org/10.1177/0049124115610348

Eadeh, F. R., \& Chang, K. K. (2019). Can threat increase support for liberalism? New insights into the relationship between threat and political attitudes. Social Psychological and Personality Science. Advance online publication. https://doi.org/10.1177/1948550618815919

Enders, W., \& Sandler, T. (1993). The effectiveness of antiterrorism policies: A vector-autoregression-intervention analysis. American Political Science Review, 87, 829-844. https://doi.org/10.2307/2938817

Finkel, E. J., \& Baumeister, R. F. (Eds.). (2019). Advanced social psychology: The state of the science (2nd ed.). New York, NY: Oxford University Press.

Gilbert, D. T., Lieberman, M. D., Morewedge, C. K., \& Wilson, T. D. (2004). The peculiar longevity of things not so bad. Psychological Science, 15, 14-19. https://doi.org/10.1111/j.0963-7214.2004.01501003.x

Google. (2017). Google Trends Help. Retrieved at https://support.google.com/trends/?hl=ko\#topic=6248052

Granger, C. W. J., \& Newbold, P. (1974). Spurious regressions in econometrics. Journal of Econometrics, 2, 111-120. https://doi.org/10.1016/0304-4076(74)90034-7 
Guimond, S., de la Sablonnière, R., \& Nugier, A. (2014). Living in a multicultural world: Intergroup ideologies and the societal context of intergroup relations. European Review of Social Psychology, 25, 142-188.

https://doi.org/10.1080/10463283.2014.957578

Haidt, J., Graham, J., \& Joseph, C. (2009). Above and below left-right: Ideological narratives and moral foundations. Psychological Inquiry, 20, 110-119. https://doi.org/10.1080/10478400903028573

Hamilton, J. D. (1994). Time series analysis (1 ${ }^{\text {st }}$ ed.). Princeton, NJ: Princeton University Press.

Hancock, C., \& Mobillion, V. (2019). “I want to tell them, I'm just wearing a veil, not carrying a gun!" Muslim women negotiating borders in femonationalist Paris. Political Geography, 69, 1-9.

https://doi.org/10.1016/j.polgeo.2018.11.007

Henderson-King, E., Henderson-King, D., \& Hathaway, L. (2009). Group favoritism and support for government policies as a function of patriotic orientation and perceived threat. Revue Internationale de Psychologie Sociale, 22(3), 235-266. Retrieved from https://www.cairn.info/revue-internationale-de-psychologie-sociale-20093-page-235.htm

Huddy, L., Feldman, S., Taber, C., \& Lahav, G. (2005). Threat, anxiety, and support of antiterrorism policies. American Journal of Political Science, 49, 593-608. https://doi.org/10.1111/j.1540-5907.2005.00144.x

Hyndman, R. J., O'Hara-Wild, M., Bergmeir, C., Razbash, S., Wang, E., \& Hyndman, M. R. (2017). forecast: Forecasting Functions for Time Series and Linear Models. R package version 8.2. https://cran.rproject.org/package=forecast

IPSOS. (2017, March). La place de la religion et de la laïcité dans l'élection présidentielle [The role of religion and secularism during the presidential election]. Retrieved from https://www.ipsos.com/sites/default/files/files-frfr/doc_associe/religions_et_laicite_mars2017.pdf

Jeffries, C. H., Hornsey, M. J., Sutton, R. M., Douglas, K. M., \& Bain, P. G. (2012). The David and Goliath principle: Cultural, ideological, and attitudinal underpinnings of the normative protection of low-status groups from criticism. Personality and Social Psychology Bulletin, 38, 1053-1065. https://doi.org/10.1177/0146167212444454

Jonas, E., McGregor, I., Klackl, J., Agroskin, D., Fritsche, I., Holbrook, C., \& Quirin, M. (2014). Threat and defense: From anxiety to approach. In J. M. Olson \& M. P. Zanna (Eds.), Advances in experimental social psychology, Vol. 49 (pp. 219-286). San Diego, CA, US: Elsevier Academic Press.

Jost, J. T. (2017). Ideological asymmetries and the essence of political psychology. Political Psychology, 38, 167-208. https://doi.org/10.1111/pops.12407

Jost, J. T., Hennes, E. P., \& Lavine, H. (2013). 'Hot' political cognition: Its self-, group-, and system-serving purposes. In D. Carlston (Ed.), The Oxford handbook of social cognition (pp. 851-875). New York, NY, US: Oxford University Press.

Jost, J. T., Nosek, B. A., \& Gosling, S. D. (2008). Ideology: Its resurgence in social, personality, and political psychology. Perspectives on Psychological Science, 3, 126-136. https://doi.org/10.1111/j.1745-6916.2008.00070.x

Jun, S.-P., Yoo, H. S., \& Choi S. (2018). Ten years of research change using Google Trends: From the perspective of big data utilizations and applications. Technological Forecasting and Social Change 130, 69-87.

https://doi.org/10.1016/j.techfore.2017.11.009

Kamiejski, R., Guimond, S., De Oliveira, P., Er-rafiy, A., \& Brauer, M. (2012). Le modèle républicain d'intégration: limplications pour la psychologie des relations entre groups [The republican model of integration: Implications for the psychology of intergroup relations]. L'année Psychologique, 112, 49-83. Retrieved from

https://www.cairn.info/revue-l-annee-psychologique1-2012-1-page-49.htm 
Kessler, T., Proch, J., Hechler, S., \& Nägler, L. A. (2015). Political diversity versus stimuli diversity: Alternative ways to improve social psychological science. Behavioral and Brain Sciences, 38, e148.

https://doi.org/10.1017/S0140525X14001241

Kteily, N. S., Rocklage, M. D., McClanahan, K., \& Ho, A. K. (2019). Political ideology shapes the amplification of the accomplishments of disadvantaged vs. advantaged group members. Proceedings of the National Academy of Sciences, 116, 1559-1568. https://doi.org/10.1073/pnas.1818545116

Kwiatkowski, D., Phillips, P. C. B., Schmidt, P., \& Shin, Y. (1992). Testing the null hypothesis of stationarity against the alternative of a unit root: How sure are we that economic time series have a unit root? Journal of Econometrics, 54, 159-178. https://doi.org/10.1016/0304-4076(92)90104-Y

Landau, M. J., Solomon, S., Greenberg, J., Cohen, F., Pyszczynski, T., Arndt, J., . . Cook, A. (2004). Deliver us from evil: The effects of mortality salience and reminders of 9/11 on support for President George W. Bush. Personality and Social Psychology Bulletin, 30, 1136-1150. https://doi.org/10.1177/0146167204267988

Lucas, B. J., \& Kteily, N. S. (2018). (Anti-)egalitarianism differentially predicts empathy for members of advantaged versus disadvantaged groups. Journal of Personality and Social Psychology, 114, 665-692.

http://dx.doi.org/10.1037/pspa0000112

Marzouki, Y., \& Oullier, O. (2012, July 17). Revolutionizing revolutions: Virtual collective consciousness and the Arab Spring. HuffPost. Retrieved from https://www.huffpost.com/entry/revolutionizingrevolutio_b_1679181?\%5B8\%2F18\%2F2016=

Marzouki, Y., \& Oullier, O. (2014). Internet search volume as a proxy approach to the Virtual Collective Consciousness. In A. D. Cheok (Ed.), Hyperconnectivity and the future of Internet communication (p. 30-58). Balti, Moldova: Lambert.

Nail, P. R., McGregor, I., Drinkwater, A. E., Steele, G. M., \& Thompson, A. W. (2009). Threat causes liberals to think like conservatives. Journal of Experimental Social Psychology, 45, 901-907.

https://doi.org/10.1016/j.jesp.2009.04.013

Napier, J. L., Huang, J., Vonasch, A. J., \& Bargh, J. A. (2017). Superheroes for change: Physical safety promotes socially (but not economically) progressive attitudes among conservatives. European Journal of Social Psychology, 48, 187-195. https://doi.org/10.1002/ejsp.2315

Neuman, W. R., Guggenheim, L., Jang, S. M., \& Bae, S. Y. (2014). The dynamics of public attention: Agenda-setting theory meets big data. Journal of Communication, 64, 193-214. https://doi.org/10.1111/jcom.12088

Nugier, A., Roebroeck, E., Anier, N., Kleinlogel, E., Chatard, A., \& Guimond, S. (2016). The psychological effects of terrorism are moderated by cultural worldviews International Review of Social Psychology, 29, 77-84.

http://doi.org/10.5334/irsp.61

Nugier, A., Oppin, M., Cohu, M., Kamiejski, R., Roebroeck, E., \& Guimond, S. (2016). « Nouvelle Laïcité » en France et pression normative envers les minorités Musulmanes [Secularism in France and Normative Pressure against Muslim minorities]. International Review of Social Psychology, 29, 15-30. http://doi.org/10.5334/irsp.11

Onraet, E., van Hiel, A., \& Cornelis, I. (2013). Threat and right-wing attitudes: A cross-national approach. Political Psychology, 34, 791-803. https://doi.org/10.1111/pops.12014

Osborne, J. W. (2010). Improving your data transformations: Applying the Box-Cox transformation. Practical Assessment, Research \& Evaluation, 15, article 12. Retrieved from https://pareonline.net/getvn.asp?v=15\&n=12 
Preis, T., Reith, D., \& Stanley, H. E. (2010). Complex dynamics of our economic life on different scales: Insights from search engine query data. Philosophical Transactions of the Royal Society A: Mathematical, Physical and Engineering Sciences, 368, 707-5719. https://doi.org/10.1098/rsta.2010.0284

Proch, J., Elad-Strenger, J., \& Kessler, T. (2019) Liberalism and Conservatism, for a Change! Rethinking the Association Between Political Orientation and Relation to Societal Change. Political Psychology.

Pyszczynski, T., Solomon, S., \& Greenberg, J. (2003). In the wake of 9/11: Rising above the terror. In T. Pyszczynski, S. Solomon, \& J. Greenberg, In the wake of 9/11: The psychology of terror (pp. 189-198). Washington, DC, US: American Psychological Association. http://dx.doi.org/10.1037/10478-009

R Core Team (2014). R: A language and environment for statistical computing. (Version 3.5) [Computer Software]. Retrieved from http://www.R-project.org/

Richard, F. D., Bond, C. F., \& Stokes-Zoota, J. J. (2003). One hundred years of social psychology quantitatively described. Review of General Psychology, 7, 331-363. https://doi.org/10.1037/1089-2680.7.4.331

Ripley, B., Venables, B., Bates, D., Hornik, K., Gebhardt, A., \& Firth, D. (2018). MASS: Support Functions and Datasets for Venables and Ripley's MASS. R package version 7.3. https://cran.r-project.org/package=MASS

Roebroeck, E., \& Guimond, S. (2015). Schooling, citizen-making, and anti-immigrant prejudice in France. Journal of Social and Political Psychology, 3(2), 20-42. https://doi.org/10.5964/jspp.v3i2.391

Roebroeck, E., \& Guimond, S. (2018). Intergroup threat, social dominance and the malleability of ideology: The importance of conceptual replication. European Journal of Social Psychology, 48, 134-149.

https://doi.org/10.1002/ejsp.2311

Rosenblatt, A., Greenberg, J., Solomon, S., Pyszczynski, T., \& Lyon, D. (1989). Evidence for terror management theory: I. The effects of mortality salience on reactions to those who violate or uphold cultural values. Journal of Personality and Social Psychology, 57, 681-690. https://doi.org/10.1037/0022-3514.57.4.681

Schielzeth, H., \& Nakagawa, S. (2013). Nested by design: Model fitting and interpretation in a mixed model era. Methods in Ecology and Evolution, 4, 14-24. https://doi.org/10.1111/j.2041-210x.2012.00251.x

Shapiro, S. S., \& Wilk, M. B. (1965). An analysis of variance test for normality (complete samples). Biometrika, 52, 591-611. https://doi.org/10.1093/biomet/52.3-4.591

Tetreault, C. (2013). Cultural citizenship in France and le Bled among teens of pan-southern immigrant heritage. Language \& Communication, 33, 532-543. https://doi.org/10.1016/j.langcom.2013.03.010

The jamovi project (2019). jamovi (Version 0.9) [Computer Software]. Retrieved from https://www.jamovi.org

Trapletti, A., Hornik, K., LeBaron, B., \& Hornik, M. K. (2018). tseries: Time Series Analysis and Computational Finance. $\mathrm{R}$ package version 0.10 . https://cran. $r$-project.org/package=tseries

van Prooijen, J.-W., \& Acker, M. (2015). The influence of control on belief in conspiracy theories: Conceptual and applied extensions. Applied Cognitive Psychology, 29, 753-761. https://doi.org/10.1002/acp.3161

Vasilopoulos, P., Marcus, G. E., \& Foucault, M. (2018). Emotional responses to the Charlie Hebdo attacks: Addressing the authoritarianism puzzle. Political Psychology, 39, 557-575. https://doi.org/10.1111/pops.12439

Vauchez, S. H., \& Valentin, V. (2014). L'affaire Baby Loup ou la nouvelle laïcité [The Baby Loup case: An illustration of new secularism]. Paris, France: LGDJ. 
Weise, D. R., Arciszewski, T., Verlhiac, J. F., Pyszczynski, T., \& Greenberg, J. (2012). Terror management and attitudes toward immigrants. European Psychologist, 17, 63-72. https://doi.org/10.1027/1016-9040/a000056

Winegard, B. M., Clark, C. J., Hasty, C. R., \& Baumeister, R. F. (2019). Low-status groups as a domain of liberal bias. Manuscript submitted for publication. Preprint available at https://www.researchgate.net/profile/Cory_Clark/publication/326144740_Lowstatus_groups_as_a_domain_of_liberal_bias/links/5c8e7397a6fdcc38175a6226/Low-status-groups-as-a-domainof-liberal-bias.pdf

Winegard, B., Winegard, B., \& Geary, D. C. (2015). Too paranoid to see progress: Social psychology is probably liberal, but it doesn't believe in progress. Behavioral and Brain Sciences, 38, e162.

https://doi.org/10.1017/S0140525X14001332

\section{Correspondence to:}

Jais Adam-Troian

Aix-Marseille University, LPS

29 Av. Robert Schuman

13100 Aix-en-Provence

France

Email: jais.ADAM(at)univ-amu.fr

Editorial record: First submission received on April 4, 2018. Revisions received on January 25, 2019, and April 18, 2019. Accepted for publication on May 21, 2019.

Editor in charge: Lenka Dedkova

\section{About Authors}

Jais Troian is an ERC post-doctoral researcher at Istanbul Bilgi University, he investigates the way societal threats (e.g. terrorism) drive intergroup conflicts through reciprocal ideological extremization.

Thomas Arciszewski is a researcher at Aix-Marseille University, he holds a PhD in Social Psychology and is interested in the way threat-regulation processes lead to ideological extremization. (Contact: thomas.arciszewski(at)univ-amu.fr).

Themistoklis Apostolidis is a Professor of Social Psychology at Aix-Marseille University and the head of the Social Psychology Laboratory (LPS, EA849). His research focuses on the links between ideological dynamics (i.e. Social Representations) and social exclusion. (Contact: themistoklis.apostolidis(at)univ-amu.fr). 